\title{
Designing Information Resource Management Systems for Knowledge Alliance Enterprises
}

\author{
Rende Feng ${ }^{1}$ and Zhiqing $\mathrm{Bao}^{2}$ \\ ${ }^{1}$ College of RongZhi, Chongqing Technology and Business University, Chongqing 400067, \\ P.R. China fengrd@ctbu.edu.cn \\ ${ }^{2}$ School of Science, Chongqing Technology and Business University, Chongqing 400067, \\ P.R. China baozq@ctbu.edu.cn
}

\begin{abstract}
In knowledge Economy Times, it's necessary for knowledge alliance Enterprise (KAE) to build up efficient, reliable information resources management system (IRMS) to make use of the information resources (IR) more availably. This article starts from the characteristics of enterprise information resources (EIR) based on knowledge alliance, analyzing the requirements of establishing IRMS, designing the total structure of system, putting forward the main functions of the detection of market dynamic environment, analysis and cooperation, aided decision making support, in the end the items which should be drew attention to in the processes of design are given in the article.
\end{abstract}

Keywords: Knowledge alliance (KA), Enterprise information resources (EIR), System design, Information resources management system (IRMS), Enterprise information service, Logic design

\section{INTRODUCTION}

In knowledge Economy Times, in order to make use of the information resources of alliance more availably, enterprise knowledge alliance with the purpose of knowledge study and innovation must build up an efficient and reliable information resources system. How to share and communicate knowledge more availably within enterprise knowledge alliance and dig out the deep values of knowledge and effectively utilize them objectively requires enterprises to build up the information resources management system, which has become the problem that needs to be resolved urgently[1].

\section{SYSTEM ANALYSIS}

System design should combine the characteristics of affectivity, common-sharing and exchanging of information resources of KAE and the feature that the main target of $\mathrm{KA}$ is to study and create knowledge etc. and also should consider that alliance

Please use the following format when citing this chapter:

Feng, R., Bao, Z, 2007, in IFIP International Federation for Information Processing, Volume 255, Research and Practical Issues of Enterprise Information Systems II Volume 2, eds. L. Xu, Tjoa A., Chaudhry S. (Boston: Springer), pp. 1545-1555. 
partners involve wide scope, which can be any organization as long as it owns professional abilities and has contributions to alliance, such as supplier, producer, agent, vendor, government, research institute, civil group and labor union. Hence the detailed system analysis needs to be done by synthesizing all factors before system design [2].

\subsection{Necessity and Feasibility Analysis}

Enterprise information resources refers to enterprise information and resources such as technical facilities, funds and talented persons and etc. related to the collection ,processing, arranging, storage, delivering to information and so on, which includes information itself and its carries, information processing, software and hardware facilities of communications as well as related standards, norms, policies, laws and regulations. In KA, EIR also has its own characteristics in addition to the characteristics of availability, infusibility, value increment, activity and so on; these characteristics objectively require building up the information resources management system (IRMS) [3-4].

\subsubsection{The Great amount of Information Resources (IR) Requires Building up a System to Handle and Analyze Data}

After Knowledge alliance (KA) has come into being, enterprises also possess the alliance partners' IR besides their own IR, all IR needs to be fully shared and developed [5]. Due to the diversity and complexity of KA partners, IR that enterprises will face will become richer and the scope of information collection will also increase greatly and the amount of information is certainly huge. These objective varieties require enterprises to build up IRMS to handle a great deal of information data [6].

\subsubsection{The Advantage Complementing of IR Requires Building up a System to Develop and Utilize IR}

The complement and innovation of knowledge (technology, technique) is the aim and foundation which knowledge alliance forms, knowledge is the most important information resource (IR). After knowledge alliance has formed, the advantage complementing of IR makes enterprises have the abilities to make up their shortages and solve the difficulties that are hard for them by establishing IRMS to achieve the advantage complementing and common research and development of IR[7].

\subsubsection{The Strong Dynamic Characteristic Requires Building up a System to Obtain the Dynamic Information}

Because the objects of EKA are very complicated, enterprises not only become alliances with enterprises, but also probably become alliances with research institutes, suppliers and retailers. In this process, the information which enterprises gain is far beyond the information that enterprises themselves can collect and its renewing speed 
also strengthen greatly, we can say that enterprises dig out, analyze, select, examine and distinguish the useful IR by establishing IRMS to satisfy the enterprises' dynamic needs for IR.

\subsubsection{The High Requirements of IR Require Building up a System to Satisfy the Increasing Information Requirements}

The requirement is a precondition that IR can become the economic resources that means participating in the reproduction as a main factor of production. The effects of mutual action and value increment that information resources vs. other resources should become the main sources of competitive advantages of enterprises', which is also the foundation that knowledge alliance arises. Only by providing each other with IR which satisfies the requirements of enterprises can knowledge alliance be formed. Building up mutual acting IRMS is an important platform to satisfy the increasing information requirements of alliance partners'.

\subsubsection{The Excellent IR Common-sharing Requires Building up a System to Exalt the Common-sharing Effect of IR}

The basic reason which KA enterprises form lies in the sharing of IR, knowledge alliance can be formed due to the non-exclusiveness of IR. The characteristics of iterated utilization and copy of IR make competition inexistent among users. Namely user A doesn't take it as a premise whether user B makes use of IR, common-sharing is an essential characteristic of the IR of KAE. Building up highly effective IRMS is the best way to realize IR common-sharing and improve utilization.

\subsection{User Requirement Analysis}

The design of EIRS based on knowledge alliance should take the knowledge management as the target at the beginning and deliver the most fitting knowledge to the most fitting person in the most fitting time so that they can make the best decision; secondly it is decided by the type of knowledge that enterprises will absorb and achieve to process different types of knowledge appropriately [7-9].

The design of IRMS is complicated system engineering; it not only involves various technical problems, but also needs a great deal of requirement and IR characteristic analysis and also have to overcome the hinder and boycott of traditional habits, hence system design must attain users' requirement.

(1)The information products which the system provides should quickly disseminate among alliance enterprises and provide the types of information products according to the requirements.

(2)The system should satisfy the enterprises in alliance with knowledge sharing function to make the communication smooth among them.

(3) The system should dig out the most useful IR utmost to attain the study and innovation of knowledge of alliance enterprises.

(4)The system should satisfy the security requirements to prevent the important and core information from being stolen. 


\section{THE TOTAL STRUCTURE DESIGN OF SYSTEM}

According to the requirement analysis above, the system has the characteristics of clear levels, strong working abilities and intelligently cooperative and interactive abilities while designing the total structure of EIRMS under knowledge alliance.(as figure 1) The system total structure design takes information center as a vital point, which links the run of the system and gives the decision making section the most powerful support. The knowledge of information center (IR) mainly originates from two parts, namely Intranetlinternet platform and Extranet platform, intranet linternet platform mainly collect IR from the macroscopic environment to attain the monitoring function of the market dynamic environment. Extranet platform mainly collect IR from knowledge alliance to realize the analytic and cooperative function of knowledge alliance enterprises (KAE). The information center establish the IR needs from decision making section of enterprise, collecting and arranging various IR and select preliminatily and at the same time keep the documents and records well and periodically put on file to attain the arrange able and keeping functions of IR; The system uses the scientifically analytic method and technology to collect IR, produce and pack IR products and deliver them to users' hands in time and provide the decision making section of enterprise with fast, friendly browsing and searching services to achieve the system-aided decision making support function[812][14].

\section{THE MAIN FUNCTIONS AND ITS LOGIC DESIGN OF THE SYSTEM}

As the core of enterprises' information management and the operating and managing camarillas of enterprises' strategies, the IRMS of KAE should have a few main functions as follows:

\subsection{The Monitoring Function of Market Dynamic Environment and Its Logic Design}

The modern market is making its way to the diversification and globalization day by day, KAE must understand the environmental information completely and accurately if they want to dig themselves into the complicated and turbulent environment and understand the future thoroughly. Only adapting to the changes of environments can enterprises exist and develop. For an enterprise of knowledge alliance, any change in exterior environment, including technologies, economies and politics will possibly have great effect on the benefits and existence of alliance. If these possible changes can be discovered and predicted in time, the corresponding measures will be adopted to avoid the threats in advance and seek for newly developing opportunities [10-12]. 
Designing Information Resource Management System of Knowledge Alliance Enterprise

1549

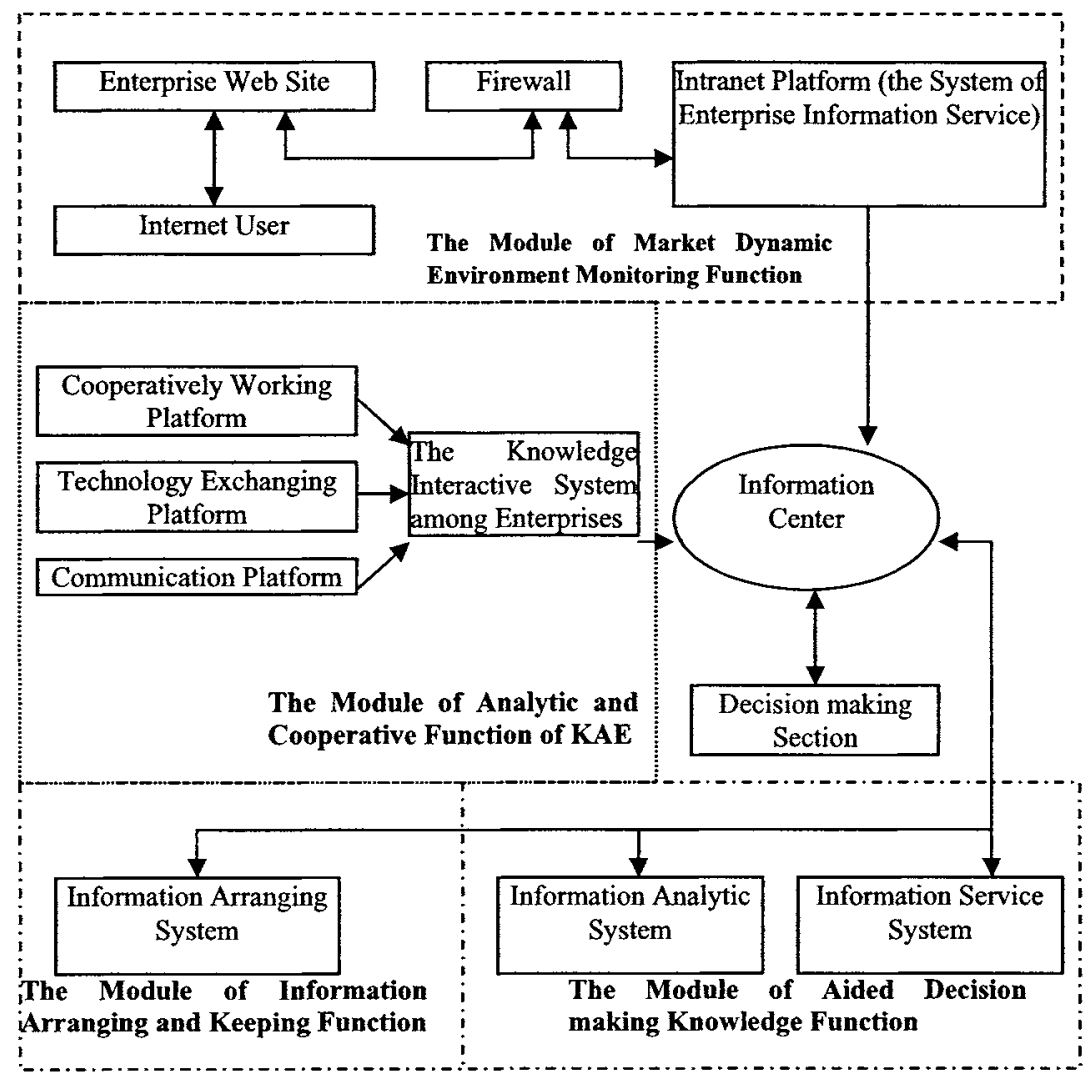

Figure 1. The Total Structure Design of IR System

In order to achieve this goal, the monitoring function of market dynamic environment is designed in the system to forecast timely and accurately and monitor the market environment to gain the enterprises more complete information, its logic design is as figure 2 .

The monitoring system of market dynamic environment collects the information of exterior environment through intranet and internet and provides employees with knowledge Conveying, share and utilization. Intranet provides enterprises with information which is got from the inner part of enterprises. Internet connects enterprises with the virtual platform of exterior environment, all outer users and enterprises can manage and gather various information resources together by using various interactive structures such as web page, voice, network TV and network pager and realize the offer and collection of IR, thus achieve the enterprises' monitoring and forecasting functions to the environments. 


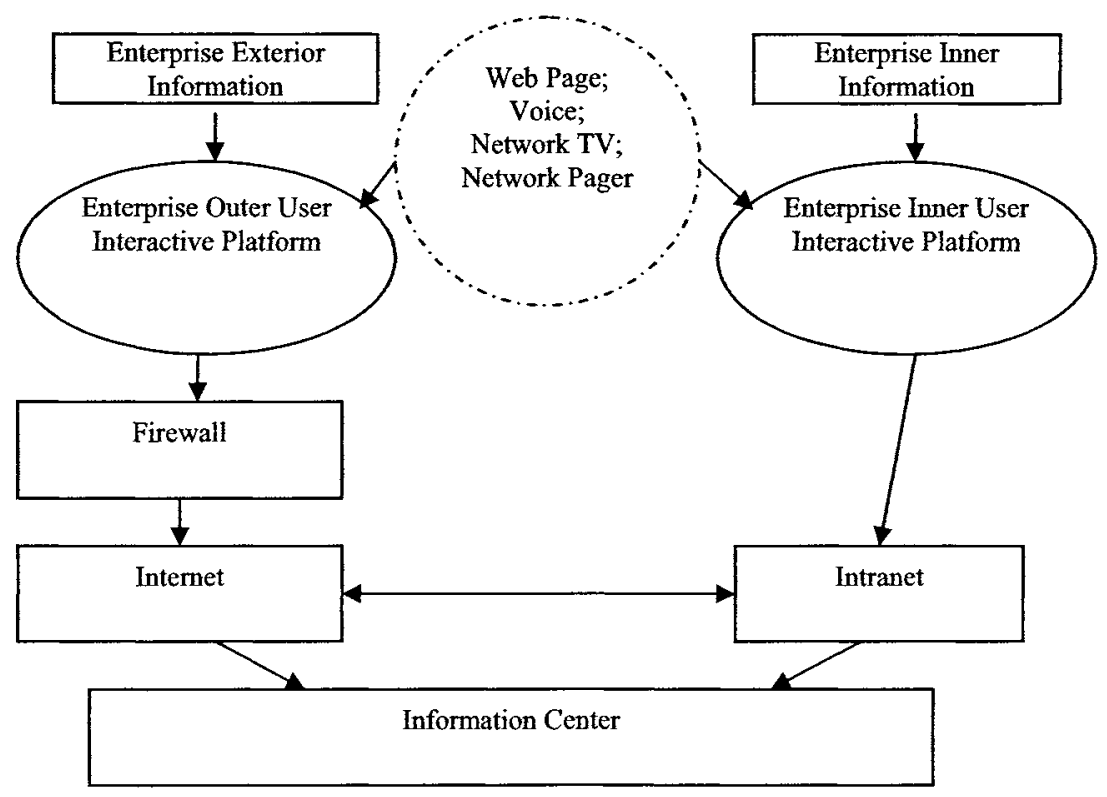

Figure 2. The Logic Design of Monitoring System of Market Dynamic Environment

\subsection{The Analytic and Cooperative Function of KAE and Its Logic Design}

The purpose of analyzing alliance enterprises is to understand the strategies and targets of each alliance enterprise and evaluate its advantages and disadvantages as well as cooperative mode and thereby formulate its own cooperative strategies and tactics. Meanwhile through the construction of IRMS, enterprises can exchange smoother with alliance partners and get more abundant knowledge (IR). The object of $\mathrm{KAE}$ is to obtain knowledge from alliance partners, therefore, the system must build up the analytic and cooperative system and be able to provide a great deal of potential knowledge resources which can be exploited and utilized so that the enterprises can exchange and share knowledge with other organizations availably [13].

The analytic and cooperative system is divided into cooperation platform, technical exchanging platform and communication platform (as figure 3). The cooperation platform can perform knowledge exchanges and shares for employees of enterprises in different geographic positions and make an item a crosses enterprises be completed quickly on that platform. Technology exchanging platform mainly provides each alliance enterprise with related technology support and exchange. 


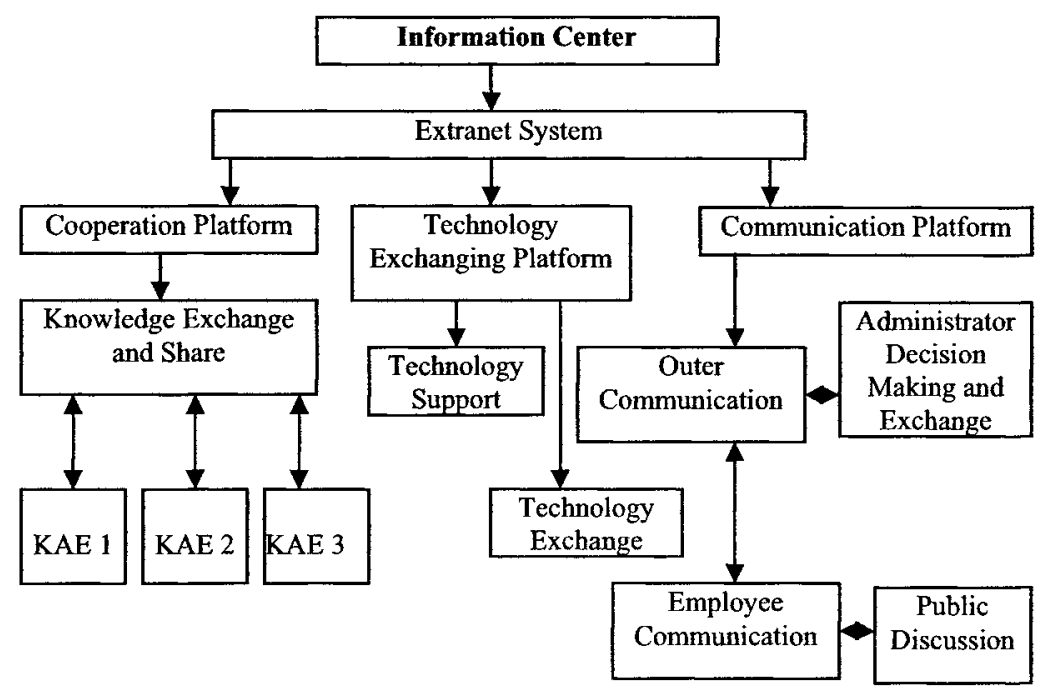

Figure 3. The Logic Design of Analytic and Cooperative System

Communication platform is divided into two parts, one is the outer layer communication platform, the emphasis is to support administrators' decision making and information exchange among alliance enterprises; Another is employees' communication platform, the emphasis is to provide a public discussion area for all employees of the alliance enterprises, the employees can discuss the businesses and exchange technologies on variously hot issues which related to enterprises and furthermore share knowledge, seek for experiences and in the meantime help realizing the cultural blend of alliance enterprises.

\subsection{Information Arranging and Keeping Function and Its Logic Design}

According to the information requirement that information center establishes from enterprise's decision making layer, enterprises need to collect and arrange various information and select preliminarily and at the same time keep the documents and records well and periodically put on file, which is the groundwork of IRMS and its work quantity and efficiency decide the effects and enterprises' benefits of this system [14-15]. By building up information arranging and keeping system, enterprises can determine the information collecting plan according to the information requirement of inner users among enterprises and fulfill the collecting task of fixed information in time and accurately according to the regulations as well as be responsible for the tracking and monitoring to alliance enterprises, market dynamic 
state, enterprises' exterior and interior environment and feedback information in time. (As figure 4)

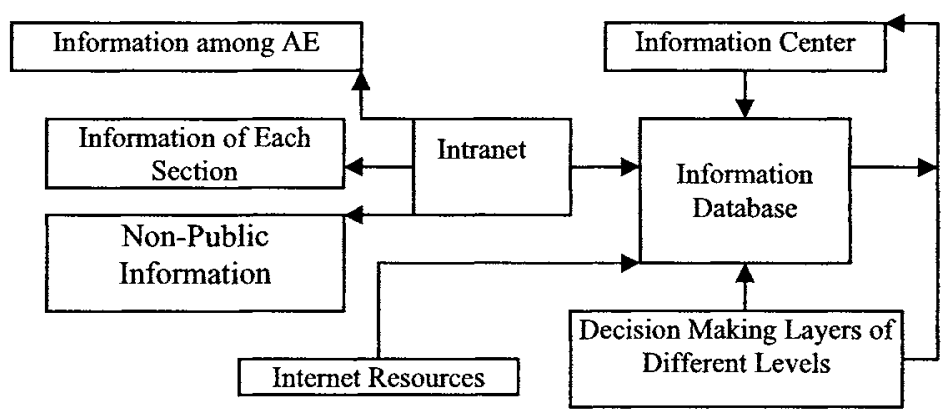

Figure 4. The Logic Design of Information Arranging and Keeping System

\subsection{Aided Decision Making Support Function and Its Logic Design}

The work of IRM of KAE is a continuous process of information analysis, which converts the original information coming from enterprises themselves, alliance partners, market needs and competitive environments into related, accurate and practical knowledge to satisfy the decision maker's needs of learning operation and management and thereby draws up the strategic plans of acquiring and maintaining competitive advantages, which requires enterprises build up a decision making support system with the functions of information analysis and information service, assisting enterprises analyzing and collecting IR and ordering, systematizing and layering IR to make decision making section get more direct, more accurate and more deeper IR products and provide enterprises decision making layers with fast and friend browse and inquiry service.(as figure 5 ) 


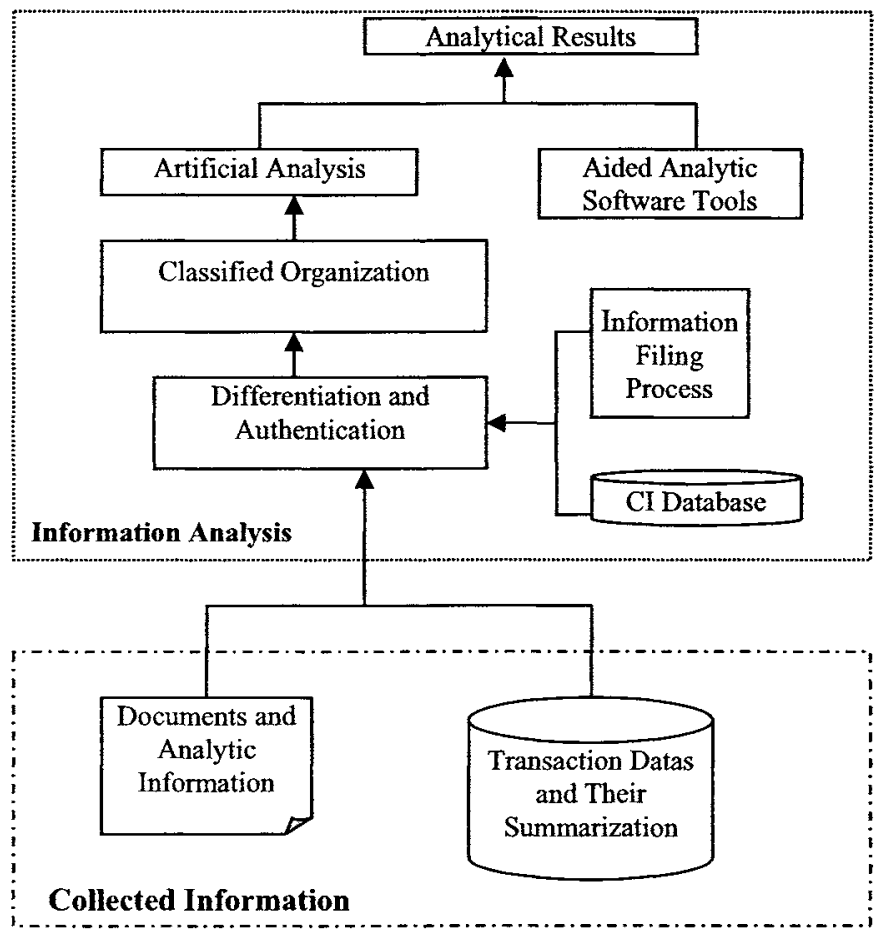

Figure 5. The Logic Design of Aided Decision Making Support System

Aided decision making support system can provide enterprises' operations and managements with special subject reports, i.e. cooperative situation analysis, market research reports and enterprise's environment analysis, looking for new developing opportunities for enterprises.

\section{THE ITEMS THAT SHOULD BE PAID ATTENTION TO IN SYSTEM DESIGN}

In the process of the EIRMS design, the items should be paid attention to as follows:

(1) Information security problem. In the process of system design, it should be considered that the core information of enterprises won't be stolen. On the one hand, the design on the network security of enterprises should be strengthened, such as the design of fire wall and ID authentication, on the other hand, the information security training for enterprises' employees should be strengthened to improve the consciousness of security defending [13][16]. 
(2) The conditions of scale, information requirement, financial standing, talented persons of alliance as well as the input/output ratio of the system should be considered comprehensively and completely balanced to design the IRMS that corresponds to the fact

(3) Taking knowledge as the center, the system should be designed by taking the valid excavation and utilization of alliance knowledge as its target.

(4)In design, we should communicate with users timely and understand the requirement in detail to make the system utmost satisfy the IRM needs of KAE.

\section{CONCLUSIONS}

The design of IRMS of KAE is a comprehensively systematic engineering and a process in proper sequence, we must analyze detailed requirements, design the system iteratively and absorb numerous experiences and lessons of the design of IRMS to avoid going through roundabout road and attain the purpose of system design. The system design put forward in this article absorbs the advanced thoughts and uses the methods of system engineering, which has certain practical meaning for KAE to build up IRMS and develop and utilize IR.

\section{REFERENCES}

1. M. Schönberger, F. Humle, P. Zeeman, Thomas, and W. Teasdale, Working Alliance and Patient Compliance in Brain Injury Rehabilitation and Their Relation to Psychosocial Outcome, Neuropsychological Rehabilitation. Volume 16, Number 3, pp.298-, (June 2006).

2. B. Wu, Strategy Analysis and System Design within an Overall Framework of Manufacturing System Management, International Journal of Computer Integrated Mamufacturing. Volume 14, Number 3, pp.319-, (May 2001).

3. X. Thao, Research on the Theories and Methods and Strategic Planning of Enterprises Information Resources Configuration. Ph.D Thesis, Jilin University (2005).

4. C. Wang, Y. Chen, Y. Chen, and C. Ho, Methodology and System Framework for Knowledge Management in Allied Concurrent Engineering, International Journal of Computer Integrated Manufacturing. Volume 18, Number 1, pp.53, (January 2005).

5. R. Li, Reliability Management for Information System, Journal of Shanghai University (English Edition). Number 5, pp.268-274, (2005).

6. J.A. Harding and K. Popplewell, Enterprise Design Information: the Key to Improved Competitive Advantage, International Journal of Computer Integrated Manufacturing. Volume 14, Number. 6, pp.514-, (2001).

7. K.L. Choy, W.B. Lee, H. Lau, D. Lu, and V. Lo, Design of an Intelligent Supplier Relationship Management System for New Product Development, International Journal of Computer Integrated Manufacturing. Volume 17, Number 8, p.692, (December 2004).

8. D. Zhang and Q. Bai, the Integration of Strategic Alliance Information System, Logistics Technology. Number 12, pp.34-36, (2002).

9. H. Liu, Exploration on the Design of Enterprise Information System, Hunan Social science. Number 1, pp.34-35, (2005). 
10. J. Zhang and H. Chen, the Analysis on the Structure Mode of Enterprise Information Resources Management System, Yang Teachers of College Journal. Number 6, pp.45-47, (2004).

11. H. Deng, The Design of Enterprise Management Information System, The Enterprise Economy. Number 6, pp.56-58, (2004).

12. J.S. Garcia and J.M.S. Dominguez, Methodology of Integrated Information Systems Design, International Journal of Computer Integrated Manufacturing. Volume 17, Number 6, pp.493-, (2004).

13. M. Salisbury and J. Plass, A Conceptual Framework for a Knowledge Management System, Human Resource Development International. Volume 4, Number 4, pp.451-, (2001).

14. N.K.H. Tang, H. Benton, D. Love, P. Albores, P. Ball, J. MacBryde, and N. Boughton, Developing an Enterprise Simulator to Support Electronic Supply-chain Management for B2B Electronic Business, Paul Drake Production Planning\& Control. Volume 15, Number 6, pp.572-, (2004).

15. M. Apple, Strategic Alliance or Hegemonic Strategy? Conservatism among the Dispossessed, London Review of Education. Volume 1, Number 1, pp.47-, (2003).

16. W. Schoenmakers and G. Duysters, Learning in Strategic Technology Alliances, Technology Analysis \& Strategic Management. Volume 18, Number 2, pp.245-, (2006). 